\title{
PAISAGENS BIOPOLÍTICAS: A PRODUÇÃO DA SAÚDE, BELEZA E POTÊNCIA CORPORAL DOS SUJEITOS FUMANTES E NÃO FUMANTES
}

\author{
Camilo Darsie ${ }^{1}$ \\ Betina Hillesheim ${ }^{2}$ \\ Douglas Luís Weber ${ }^{3}$
}

\begin{abstract}
RESUMO: Este artigo tem por objetivo analisar algumas das pedagogias culturais relacionadas ao controle do tabagismo. Entende-se que, por meio das paisagens urbanas, as campanhas de combate ao fumo instituem saberes e pautam comportamentos considerados mais adequados quando avaliados pelos preceitos da saúde, operando sobre a população em espaços não formais. Nesta direção, as paisagens urbanas podem ser pensadas como pedagogias culturais já que funcionam como tecnologias biopolíticas que produzem sujeitos engajados no que se refere ao controle e à manutenção de seus corpos e saúde. Nesta direção, a beleza e a potência física estão diretamente associadas à saúde.
\end{abstract}

Palavras-chave: Saúde - Pedagogias Culturais - Biopolítica

\section{BIOPOLITICAL LANDSCAPES: THE PRODUCTION OF HEALTH, BEAUTY AND BODY POTENCY OF SMOKERS AND NO SMOKERS SUBJECTS}

\begin{abstract}
This article analyze some of the cultural pedagogies related to tobacco control. It is understood that, through urban landscapes, campaigns to combat smoking are instituting knowledge and guiding behaviors considered more appropriate when evaluated by health precepts, operating over the population in non-formal spaces. In this direction, urban landscapes can be thought of as cultural pedagogies since they function as biopolitical technologies that produce subjects engaged in the control and maintenance of their bodies and health. In this direction, beauty and physical potency are directly associated with health.
\end{abstract}

Keywords: Health - Cultural Pedagogies - Biopolitics

\footnotetext{
${ }^{1}$ Professor adjunto do Departamento de História e Geografia da Universidade de Santa Cruz do Sul - UNISC e Colaborador do Programa de Pós-graduação em Educação (PPGEdu) da mesma instituição. Doutor em Educação pela Universidade Federal do Rio Grande do Sul (UFRGS), com Doutorado Sanduíche Internacional no Department of Geography, Environment \& Society (Departamento de Geografia, Meio Ambiente e Sociedade) da University of Minnesota - Estados Unidos, sob supervisão do Dr. Bruce Braun. Possui mestrado em Educação (2006) e graduação em Geografia pela Universidade Luterana do Brasil (2003). Faz parte do grupo de pesquisa Identidade e Diferença na Educação da UNISC. Tem experiência nas áreas de Geografia, Educação e Saúde atuando principalmente nos seguintes temas: Estudos Culturais em Educação, Geografia Humana, Geogafia da Saúde e Educação em Saúde.

${ }^{2}$ Professora adjunta e pesquisadora do departamento de Psicologia e do Programa de Pós-Graduação (Mestrado e Doutorado) em Educação da Universidade de Santa Cruz do Sul. Possui graduação em Psicologia pela Pontifícia Universidade Católica do Rio Grande do Sul (1989), mestrado em Psicologia Social e da Personalidade pela Pontifícia Universidade Católica do Rio Grande do Sul (2001) e doutorado em Psicologia pela Pontifícia Universidade Católica do Rio Grande do Sul (2006). Membro do comitê assessor da Fapergs, nas áreas de Educação e Psicologia (2013-2014, 2015-2016).

${ }^{3}$ Mestrando e Bolsista BIPSS (Programa de Bolsas Institucionais para Programas de Pós-Graduação Stricto Sensu) do Programa de Pós-Graduação em Educação da Universidade de Santa Cruz do Sul (UNISC), Professor do Governo do Estado do Rio Grande do Sul, possui graduação em Geografia Licenciatura pela Universidade de Santa Cruz do Sul (UNISC).
} 


\section{Introdução}

O presente artigo se fundamenta em uma análise sobre as campanhas de promoção da saúde voltadas ao controle do tabagismo. Tais iniciativas estão alinhadas com o artigo 14 do WHO Framework Convention on Tobacco Control - FCTC, tratado internacional do qual o Brasil é um dos países signatários, e que dispõe sobre medidas de redução da dependência do fumo e cessação do tabagismo. Entre essas medidas, são previstas diferentes ações a serem desenvolvidas por distintos agentes (profissionais de saúde, assistentes sociais, trabalhadores comunitários, etc.) e espaços (instituições educacionais, estabelecimentos de saúde, locais de trabalho, ambientes esportivos, etc.), mediante a realização de programas, planos e estratégias de saúde e educação (WHO, 2003). Nesse sentido, em 2002, por exemplo, o Brasil adotou a obrigatoriedade de uso de imagens de advertência sobre os malefícios do tabagismo nas carteiras de cigarros e demais artefatos ligados à comercialização destes, como parte de medidas restritivas ao fumo por parte da população.

Desse modo, entendemos que as campanhas de promoção da saúde promovidas, principalmente, por Organizações Internacionais, como a Organização Mundial da Saúde, e órgãos públicos brasileiros como o Ministério e as Secretarias da Saúde, buscam interpelar a população, constituindo-se como pedagogias culturais. Nos últimos anos, é possível perceber que tais campanhas têm sido veiculadas nas mais diferentes situações e lugares, inclusive com o apoio do setor privado, o qual, estimulado por essas ações e pelas pesquisas sobre promoção de saúde e controle do tabagismo, vem criando suas próprias campanhas e artefatos midiáticos voltados aos efeitos do cigarro. Assim, diversos outdoors, cartazes e panfletos circulam pelo espaço - espaço esse que, no âmbito Geografia, passa a ser conhecido como espaço geográfico -, com a proposta de informar/educar a população no que diz respeito aos comportamentos ideais a serem seguidos por aqueles que prezam pela saúde.

Portanto, para a realização da discussão sobre as campanhas de combate ao fumo, partimos do pressuposto que estas se constituem como pedagogias culturais. Como discutem Andrade e Costa (2017), a expressão pedagogias culturais passou a ser disseminada, no Brasil, há cerca de duas décadas, a partir do campo dos Estudos Culturais, tornando-se uma ferramenta conceitual bastante produtiva. Ao se debruçarem sobre a emergência desse conceito, as autoras discutem que uma das questões centrais que contribuiu para sua fabricação foi a ampliação da própria noção dos lugares de aprendizagem, os quais extrapolam 
o espaço escolar. Nessa perspectiva, Noguera-Ramirez (2009), ao discutir a genealogia do conceito de aprendizagem, afirma que vivemos em uma sociedade saturada pela educação: enquanto a Modernidade se pautou, entre os séculos XV e XVII, como uma sociedade de ensino, na sociedade pós-capitalista, o que se coloca em questão é uma sociedade de aprendizagem. Assim, esse deslocamento de uma noção de ensino para aprendizagem apoia-se numa governamentalidade neoliberal, isto é, uma forma de governamento que, através da autonomia, da liberdade, dos interesses e da autorregulação, busca governar menos para governar mais, potencializando forças e investindo maciçamente na vida. Nesse sentido, a aprendizagem não se traduz em uma forma, mas se relaciona com uma ideia de flexibilidade, plasticidade. Dessa maneira, a sociedade se torna uma sociedade educativa, mediante tanto uma constante oferta de oportunidades educativos para seus membros, quanto pela exigência de uma busca permanente por educação. Além disso, embora o autor assinale que já no projeto de Comenius - ensinar tudo a todos - havia uma proposta de se pensar o mundo como uma escola, mediante uma maquinaria escolar universal, na contemporaneidade a novidade reside no próprio conceito de aprendizagem e a constituição de um sujeito denominado como Homo discens.

Hillesheim (2015), ao discutir a ideia de Bauman referente à modernidade líquida, num mundo que continuamente se desfaz, propõe pensar que, mais do que a transformação do mundo em uma escola, como imaginado por Comenius, o que temos hoje é a dissolução da própria solidez da escola. "Uma educação que não está em algum lugar, que não é alguma coisa, mas que se multiplica na conjunção 'e': na sala de aula $e$ na mídia $e$ na família $e$ no trabalho e nas políticas públicas $e .$. . Uma educação que está em todo lugar e da qual nos nutrimos permanentemente" (p. 791). Além disso, Andrade e Costa (2017), ao compreenderem que essa dispersão dos lugares de aprendizagem é uma das características do imperativo pedagógico de nosso tempo, citam Ellsworth como uma das autoras que posiciona a pedagogia em uma função articuladora de tal movimentação. Ellsworth, em seu livro Places of Learning, publicado em 2005, sugere que, diante dos diferentes lugares de aprendizagem, sejam adotados novos ângulos de análise, a partir da compreensão que esses são espaços pedagógicos, bem como nomeando como "força pedagógica as qualidades pedagógicas que cada um desses lugares possui" (ELLSWORTH, 2005 apud ANDRADE; COSTA, 2017, p. 7). 
Diante dessa situação, tomamos como objeto de análise alguns desses materiais que, na maioria das vezes, são elaborados a partir de enunciados e imagens que (re)produzem representações associadas aos sujeitos aos quais pretendem interpelar. Mais especificamente, analisamos materialidades (panfletos, cartazes e demais peças publicitárias) que, relacionadas aos discursos de combate ao fumo, circulam pelo espaço público, inseridas em movimentos de conscientização, apresentando mensagens que relacionam a saúde à beleza e/ou à potência corporal. Assinalamos, assim, que há um entrelaçamento entre os discursos sobre corpos saudáveis, fortes e belos e sobre a possibilidade de ser perder tais atributos diante do consumo de tabaco.

Outra questão a ser destacada refere-se ao posicionamento e circulação dos materiais utilizados por essas campanhas. No que diz respeito aos estudos realizados pelos pesquisadores do campo da Geografia, essas ações de conscientização/educação constituem, ao mesmo tempo em que são constituídas, pelos atravessamentos culturais que ocorrem no espaço geográfico, ou seja, aquele espaço amplo no qual as diferentes pessoas e os diferentes comportamentos e ações se localizam (DARSIE, 2006). No entanto, considerando a impossibilidade de dar conta de uma dimensão tão extensa, optamos por fazer um recorte analítico por meio de um dos conceitos operacionais do campo da Geografia que oportunizam olhar para o espaço (SURTEGARAY, 2001), qual seja, a Paisagem. Assim, consideramos o espaço público urbano e, mais especificamente, as paisagens que o compõem, tendo em vista diferentes escalas.

Partindo de tais questões, o artigo discute, por meio do cruzamento das áreas da Saúde, da Educação e da Geografia, articuladas pelas lentes dos Estudos Culturais, os discursos sobre o corpo contidos nas campanhas de Promoção da Saúde relacionadas ao fumo que circulam em paisagens urbanas. Para realizar tal intento, o texto se organiza da seguinte forma: em um primeiro momento, trazemos a delimitação do espaço de análise e a configuração da paisagem como pedagogia cultural; a seguir, problematizamos os discursos sobre saúde associados às noções de beleza e força física e, para finalizar, buscamos mostrar como as campanhas de combate ao fumo (re)produzem tais articulações, operando como potentes pedagogias culturais que instituem corpos de fumantes de determinadas maneiras e não outras. 


\section{Paisagem E Pedagogias Culturais: Algumas Aproximações}

Como assinalado na introdução deste texto, um dos conceitos que oportuniza aproximações, análises e problematizações que entrelaçam os Estudos Culturais à Educação, especialmente no Brasil, é o de pedagogia cultural. Tal conceito tem sido mencionado e operado em muitos casos por pesquisadores que buscam dar conta de variados processos educativos que extrapolam os muros e/ou demarcações das instituições historicamente vinculadas à aprendizagem, como, por exemplo, a escola (WORTMANN, COSTA e SILVEIRA, 2015).

Neste sentido, as autoras recorrem à obra Teoria cultural e educação: um vocabulário crítico com o objetivo de demonstrar que por pedagogia cultural entende-se "qualquer instituição ou dispositivo cultural que, tal como a escola, esteja envolvido - em conexão com relações de poder - no processo de transmissão de atitudes e valores" (SILVA, 2000, apud WORTMANN; COSTA e SILVEIRA, 2015, p. 37). Assim, emerge a possibilidade de se pensar, de maneira mais consistente, que a aprendizagem é praticada também por meio de diferentes estratégias que se distanciam dos ambientes e práticas educativas tradicionalmente configuradas como tais. Diante disto, as pedagogias passam a compor uma rede de produção cultural que têm no cotidiano e, no caso da análise aqui realizada, no espaço público urbano, a ocasião e a área em que se configuram determinadas estratégias que movimentam os sujeitos no sentido de aprendizagens relativas aos preceitos da Promoção da Saúde e de cuidado com o corpo.

Isto nos leva a entender que diferentes mídias passam a ter lugar de destaque no que se refere à produção de sujeitos. Andrade e Costa (2015) argumentam que a articulação entre os campos da Educação e da Comunicação têm alargado a possibilidade de discussões que envolvem processos pedagógicos. Para as autoras, essa aproximação oportuniza novos e ampliados olhares sobre as implicações dos artefatos midiáticos no que se refere à constituição dos sujeitos de nossos tempos. Deste modo, "textos televisivos, jornalísticos, radiofônicos, publicitários, fotográficos, fílmicos, assim como aqueles das assim chamadas novas mídias, conectadas a World Web Wide, são apenas alguns componentes desse universo midiático sempre em expansão" (p. 52).

Na mesma direção, Darsie e Santos (2012) apontam que as discussões relativas às pedagogias culturais consideram diferentes temáticas e artefatos que podem, conforme as 
necessidades dos autores/investigadores, problematizar produções cinematográficas, campanhas publicitárias, campanhas de saúde, entre outras, por meio da articulação entre áreas do conhecimento distintas, como, por exemplo, a Educação, a Geografia e a Saúde. Dessa maneira, as campanhas de Promoção da Saúde relacionadas ao combate ao tabagismo se apresentam como artefatos que circulam - e produzem - pelo espaço, lembrando a todos que o ato de fumar os afasta daqueles preceitos considerados mais corretos e, ainda, que isto pode ocasionar consequências físicas que contrariariam determinados ideais de beleza e potência física. Para Wortmann, Costa e Silveira (2015) é esta, justamente, a lógica constitutiva que transforma a pedagogia em uma tecnologia que regula sujeitos, por meio de práticas culturais direcionadas à modificação dos modos de ser.

A este respeito, Costa e Andrade (2015), ao analisarem produções acadêmicas relativas à utilização do conceito de pedagogias culturais, chamam a atenção para as discussões que evidenciam o quanto os artefatos educam, regulam condutas e subjetivam sujeitos. Elas destacam, entre outros pontos, a recorrência de questões relativas à emergência de valores e hábitos adequados que passam a circular por meio dos modos de ser de diferentes componentes da sociedade.

Para prosseguirmos nessa discussão, considerando a articulação feita entre as diferentes áreas do conhecimento no âmbito deste trabalho, entendemos como necessário fazermos algumas delimitações e escolhas no que concerne ao uso de conceitos relativos às questões espaciais. Destacamos que o espaço geográfico representa a categoria mais ampla no que se refere às análises que se inscrevem no contexto geográfico. Assim, compreendemos o espaço geográfico urbano e a paisagem como importantes ferramentas utilizadas pelos órgãos responsáveis pela divulgação das campanhas de promoção da saúde, as quais visam a educar os diferentes sujeitos a partir de informações sobre os efeitos do tabagismo sobre seus corpos.

O espaço geográfico deve ser considerado como a acumulação desigual de tempos, isto é, o espaço onde diferentes costumes, tecnologias e informações circulam de forma desigual, permitindo, assim, uma reflexão sobre o espaço na qual se considere que sua constituição se dá pela coexistência de tempos. Em consequência disso, resultam diferentes ritmos de vida e coexistências, constituindo materializações diversas que dão forma a relações complexas e carregadas de heranças, bem como de novas possibilidades (SANTOS, 1997). Neste sentido, velhas e novas maneiras de ver e pensar questões relativas, por exemplo, à 
saúde, à beleza, à força física e ao gênero, interagem, atravessando-se mutuamente e competindo entre si, dando forma a novas possibilidades de entendimento, assim como à construção de elementos materiais que possam envolvê-las.

Ainda sobre o conceito de espaço, Salgueiro (1997), Suertegaray (2001), Castilho e Frederico (2010), entre outros autores, referem que este pode ser compreendido como formas e conteúdos, mediante a integração entre materialidade e ações sociais que o movimentam e o modificam. A partir disso, podemos pensar que as ações sociais ligadas aos cuidados com a saúde, assim como as campanhas que os promovem, configuram determinadas formas de funcionamento dos espaços públicos, ou seja, tais espaços, ao identificar os sujeitos que por eles circulam, produzem diferentes endereçamentos para suas mensagens. Um exemplo desses diferentes endereçamentos é uma campanha citada por Szklo (2009) sobre uma estratégia de recrutamento reativo para serviços de aconselhamento telefônico de suporte à cessação do ato de fumar utilizada no metrô do Rio de Janeiro, a partir do tema “fumar é perder o fôlego". Outro caso que segue na mesma direção, é a rede de informações que se constitui por meio de filmes, ações educativas escolares, matérias veiculadas em jornais e revistas, entre outros, apontadas por Darsie (2006). A partir desses exemplos, evidenciamos que tais mensagens podem ser postas em circulação de diversas maneiras, mas neste trabalho, discutiremos aquelas que são promovidas através da paisagem, em diferentes escalas.

A paisagem pode ser considerada como um conceito operacional que nos permite observar o espaço geográfico a partir de dada perspectiva, ou seja, um conceito que nos permite analisar o espaço sob uma dimensão que considera a conjunção de elementos naturais e tecnificados, socioeconômicos e culturais sobrepostos e interligados. Paisagem é aquilo que vemos e que nos interpela de alguma forma através de sua materialidade e das transformações que nela ocorrem (SILVA, 2015). Segundo Carlos (1994), "a paisagem aparece como forma de manifestação do espaço geográfico superando a ideia de paisagem como elemento estático" (p. 15).

A paisagem pode ser definida como a primeira forma de aproximação do espaço, constituindo um elemento de leitura do mundo. Tal categoria operacional se torna um elemento de leitura porque é nela que podemos encontrar, e que estão estampados, os fenômenos e as formas que nos permitem chegar às relações sociais e, a partir disso, à produção e reprodução do espaço. Isso nos possibilita questionar o que vemos, não 
permanecendo, somente, na descrição daquilo que é visto. É necessário entender e criticar o que está no espaço, ou seja, não se contentar apenas com a forma, mas também buscar o seu conteúdo. Se entendermos que a paisagem está relacionada com o espaço, necessariamente estará associada à produção e à reprodução do espaço, bem como às relações sociais existentes nele, pois não há como pensar na paisagem de uma cidade sem pensar em tais questões (CARLOS, 1994).

Além disto, destacamos que a paisagem pode ser vista a partir de diferentes escalas. Neste sentido, podemos pensar que ao mesmo tempo em que observamos as materialidades comumente entendidas como paisagem - prédios, ruas, campos, florestas e outros recortes amplos -, é possível aproximar o olhar de modo a fazer leituras que consideram elementos mais detalhados. Neste caso, a paisagem engloba, entre outras coisas, os artefatos midiáticos, manifestações sociais e culturais e, conforme apontamos aqui, campanhas de saúde. Sobre as questões recém referidas, Silva (2015) argumenta:

No estudo da paisagem, antes de qualquer coisa, é necessário considerar dois princípios básicos: a escala de análise e a especificidade da percepção do observador. A escala varia de acordo com a localização, ampliando-se o seu campo na medida em que se eleva a altura, seja em uma escada, prédio, morro, avião, etc. Quanto à percepção do observador, essa é distinta, as formas e a vida serão capturadas pelos observadores, mas o modo de analisar a paisagem é particular a cada indivíduo, em muitos casos há uma predominância da descrição do imediato, escapando a sua subjetividade, o seu movimento, a dinâmica do espaço (SILVA, 2015, p. 241).

Nessa perspectiva, destacamos que, de acordo com Sarlo (2009), as cidades, por meio de suas estruturas e dinâmicas, também podem ser pensadas como mídia. Partindo de discussões que envolvem os shopping centers, as dinâmicas de exclusão e os estrangeirismos em Buenos Aires, ela refere as manifestações que compõem as metrópoles contemporâneas. Neste caso, destacam-se os grafites em muros e paredes, as publicidades em outdoor, as pichações, etc. Tais questões, entre outras, do ponto de vista em que operamos neste texto, se manifestam por meio da paisagem, fato que nos oportuniza pensar que as campanhas de combate ao fumo, ao circularem pelo espaço, também compõem a paisagem.

A partir dessas considerações sobre espaço e paisagem, buscamos aproximar o conceito de paisagem à circulação e disposição de panfletos, cartazes e outdoors como pedagogias culturais. Tais manifestações interpelam (por sua presença física), de alguma 
maneira, a todos que compõem o espaço e, ainda, ao serem planejadas, levam em conta a distribuição espacial dos diferentes tipos de sujeitos que circulam em diferentes áreas do espaço público urbano, de modo a garantir que a disposição de enunciados e de imagens interpelem determinados grupos sociais. Portanto, o uso de tais paisagens como locais de divulgação das campanhas de combate ao fumo se constituem como artefatos culturais que, ao educar os sujeitos sobre os efeitos do ato de fumar sobre seus corpos e sua saúde, praticam uma pedagogia e produzem determinadas formas de subjetivação. Deste modo, argumentamos que as paisagens, em si, podem ser tomadas como pedagogias culturais que ensinam a respeito de diferentes questões.

\section{Campanhas de promoção da saúde: pedagogias culturais que produzem sujeitos saudáveis}

Na perspectiva em que se insere este trabalho é relevante destacar que discursos sobre a saúde da população e dos indivíduos não surgiram recentemente. Foucault (1999) discute, a partir do conceito de biopolítica, que as sociedades industriais são marcadas por uma forma de poder que investe maciçamente na vida, voltando-se para o controle da população a partir da saúde pública. Para o autor, as biopolíticas são constituídas por uma gama de tecnologias de poder, com foco na população, entendida como um conjunto de seres vivos coexistentes que apresentam traços biológicos particulares e que, em função disso, são investidos com técnicas e saberes específicos. Assim, "com o Estado Moderno vemos uma profusão de pequenas rotinas canalizadas ao incremento da saúde, normalidade e consequente capacidade de produção-circulação de riquezas entre seus cidadãos” (COSTA, 2017, p. 203). Neste cenário, a Estatística ocupa um papel central, pois, como aponta Santos (2011), entre essas tecnologias de poder estão as tabelas, os gráficos e as porcentagens, os quais possibilitam a regulação e controle de fenômenos que não podem ser reduzidos ao nível individual, mas só podem ser compreendidos pela noção de população.

Além disso, no caso das sociedades contemporâneas, tem sido discutido um fenômeno nomeado como culto ao corpo, visto que

a corporeidade passou a ocupar um papel central, ou seja, nos preocupamos cada vez mais com a performance, as aparências, a estetização da vida. Uma das evidências dessa tendência é a forte e constante preocupação dos 
indivíduos com a apresentação e a forma de seus corpos, na tentativa de adequá-los a um ideal hegemônico de beleza jovem, magra e exercitada (FIGUEIREDO; NASCIMENTO; RODRIGUES, 2017, p. 70).

Conforme os autores acima, tal fenômeno é produzido e sustentado por uma série de discursos públicos e privados, bem como por uma rede de práticas, relacionando-se estreitamente com a própria formação reflexiva das identidades na contemporaneidade. Fundamentados em Giddens (1991 apud FIGUEIREDO; NASCIMENTO; RODRIGUES, 2017), assinalam que estamos hoje engajados numa "política da vida", ou seja, continuamente inseridos em lutas que pretendem ampliar as possibilidades de uma vida plenamente realizada e satisfatória para todos e para a qual não existe espaço para outros. Assim, somos constituídos como seres reflexivos, voltados para um exame permanente de nós mesmos e com um sentimento de insatisfação com aquilo que vemos. Para tanto, é necessário um monitoramento rotinizado do corpo, visto que a competência social significa não apenas a capacidade de realizar tal controle, mas também de ser percebido pelos demais como alguém que consegue exercer esse controle. Entre as formas de alcançar esse reconhecimento podem ser citadas as dietas, o vestuário, os cosméticos, os hábitos de higiene, os cuidados e a manipulação do corpo, etc. Nesse sentido, na medida em que o corpo se coloca dentro do fenômeno da reflexividade e é tido como o aspecto visível do eu, o culto ao corpo coloca-se como um imperativo na cultura ocidental contemporânea, causando sentimentos de culpa ou de inadequação naqueles que não o exercem.

Podemos pensar, portanto, que as campanhas de saúde, enquanto pedagogias culturais, são, por um lado, estratégias de investimento na vida das populações, como forma de potencializar suas forças, e, por outro, também podem ser entendidas como uma forma de produção de sujeitos reflexivos, os quais são continuamente convocados a se autoexaminarem e se responsabilizarem pelos seus atos. No caso das políticas e dos programas de saúde, Nettleton (1997) explica que não se trata somente de uma imposição do Estado sobre a população, mas é esperado que ela participe ativamente como fiscalizadora no que diz respeito à conduta de outros sujeitos em relação a esses programas. Para Street (2004), os discursos governantes colocam a responsabilidade pelos cuidados com a saúde exclusivamente nas mãos dos indivíduos, criando, assim, poderosos efeitos de verdade que reduzem estruturas disciplinares complexas a mensagens simples de causa e efeito. Por sua vez, Castiel (1999) 
argumenta que, através da circulação desses discursos nas diferentes mídias, se criou um clima em que parece pairar uma aura de ameaça sobre todos nós, passível de ser efetivada de modo particularizado, a qualquer instante.

Assim, na medida em que as campanhas de Promoção da Saúde ditam, através de seus discursos e das mais diferentes formas de linguagem, o modo certo de administrar a vida e de cuidar do corpo, elas elegem ou constituem sujeitos de determinadas formas. Para isso, são ofertadas dadas posições de sujeito que, de certa maneira, são considerados exemplos por seus modos de portar-se, controlar-se, vestir-se e de apresentarem-se esteticamente. Seguindo essa lógica, a partir das imagens que compõem as campanhas de promoção da saúde, espalhadas pelas paisagens urbanas, frequentemente são fabricadas e/ou reforçadas representações de corpos que aproximam as noções de saúde e de beleza ao ato de não fumar e, consequentemente, afastam estas representações daqueles sujeitos que fumam.

Para Silva (2000), no contexto dos Estudos Culturais, a análise da representação concentra-se em sua expressão como 'significante', como uma pintura ou uma imagem. Hall (1997) diz que a representação é o resultado da produção e troca de significados entre os sujeitos que participam de uma mesma sociedade. Segundo Hall (op. cit.), a representação pode ser explicada como sendo um processo no qual os membros de uma determinada cultura usam a linguagem a partir de diferentes formas, como textos e imagens, com o objetivo de produzirem significados em relação às coisas ou pessoas. A partir disso é coerente pensar que os objetos, as pessoas e os eventos do mundo não têm em si, naturalmente, qualquer significado estabelecido que seja permanente ou verdadeiro. Para o autor, é a sociedade que faz as coisas terem significados. Sendo assim, os significados, sempre mudam de uma cultura ou época para outra.

Em relação à representação, é também oportuno dizer que no campo dos Estudos Culturais existe um grande interesse pelas relações entre representação e identidade cultural, afirmando-se que não há identidade fora da representação. Silva (1999), por exemplo, refere que aquilo que pode ser chamado de política de identidade reúne duas dimensões da representação que estão ligadas, não podendo ser separadas. Uma delas seria a ideia de representação como delegação. Nesse caso é importante pensar em quem representa quem, ou seja, quem tem o direito de representar o outro, ou talvez o grupo. O autor esclarece ainda que, a delegação de determinados sujeitos para falar e agir em nome dos demais cria uma situação 
em que a representação do grupo fica dirigida por quem possui esta posição de delegação, uma vez que quem representa o grupo, define a forma de falar e descrever tal grupo.

Atualmente, em relação às campanhas de promoção da saúde é possível se dizer que elas se valem, de certa forma, dessa mesma lógica, ao apresentarem belos homens e belas mulheres como referenciais de saúde e, também, ao indicarem a possibilidade de perda da beleza quando se prejudica a saúde do próprio corpo.

Nesta direção, conforme discutiremos abaixo, a beleza e a potência física estão diretamente associadas à saúde, principalmente, quando analisadas por meio das campanhas que constituem as paisagens biopolíticas, ou seja, as paisagens urbanas por onde circulam as campanhas de saúde.

\section{Paisagens biopolíticas e a educação acerca da saúde, beleza e potência corporal}

As campanhas de Promoção da Saúde, ao serem problematizadas enquanto pedagogias culturais, podem ser entendidas como estratégias midiáticas que, articuladas às paisagens urbanas, oportunizam dadas aprendizagens acerca dos modos de autocuidado e estilo de vida. No que se refere às campanhas de combate ao tabagismo, em muitos casos, os não fumantes são representados por pessoas jovens, alegres, magras, com pele bem tratada, músculos delineados e, ainda, por outras marcas sociais associadas aos ideais de beleza e potência corporal em voga na nossa cultura.

Um exemplo destas campanhas apresenta-se no cartaz apresentado abaixo, produzido e veiculado a diferentes mídias e ambientes pelo Ministério da Saúde brasileiro. Nele, quatro jovens que, conforme pode ser entendido, não fumam, se divertem na praia. Neste caso, dois homens carregam, em suas costas, amigas, enquanto correm na areia. Todos sorriem, indicando que, apesar desta atividade requerer certa força física, é possível fazer isto com certa facilidade. A articulação da imagem ao enunciado apresentado "viver bem é viver com saúde fique longe do cigarro" sugere que o que devemos aprender é que ao não fumar, entre outras coisas, podemos replicar tal prática e/ou estilo de vida. 


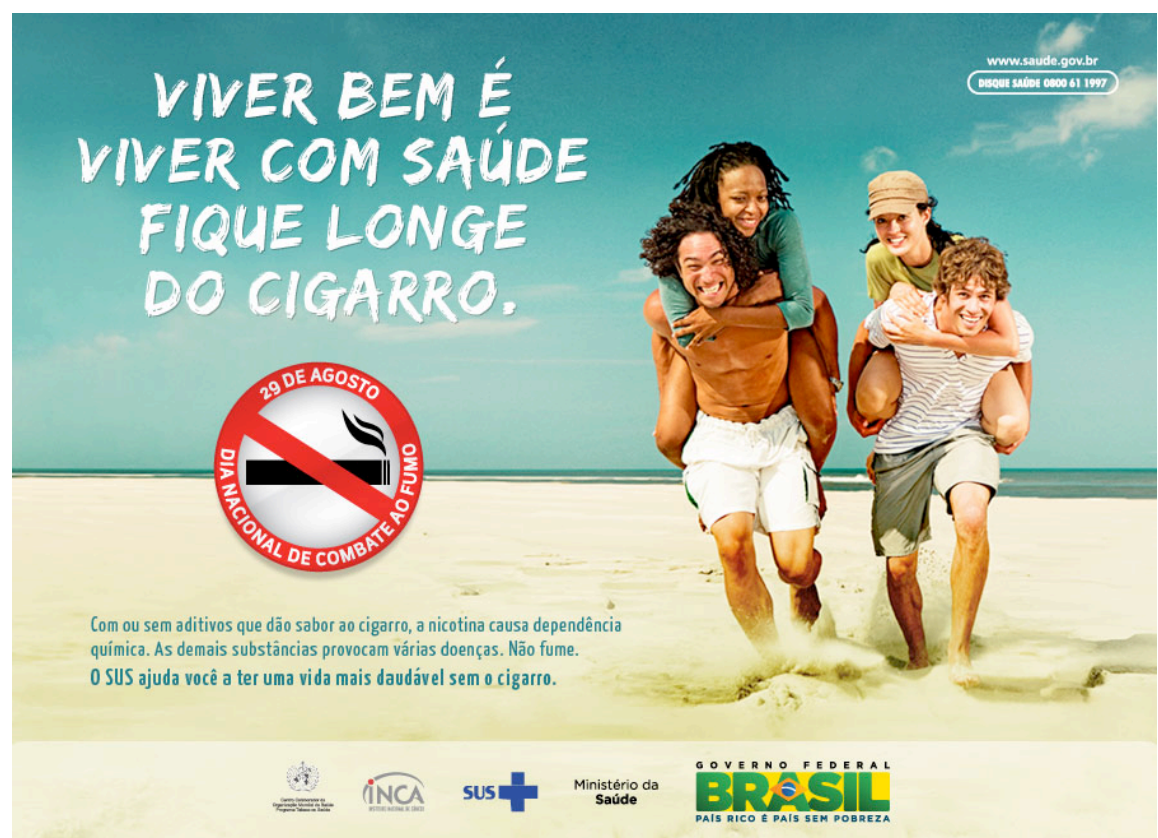

Figura 1 - Campanha antitabagismo promovida pelo Ministério da Saúde do Brasil. Fonte: Ministério da Saúde

Por outro lado, as representações associadas à falta de saúde, apresentadas nessas campanhas, indicam, muitas vezes, a possibilidade de perda desses atributos físicos como consequência de comportamentos de risco que devem ser evitados. Assim, apresentamos a seguir mais dois exemplos. O primeiro diz respeito à uma campanha produzida e divulgada pela Organização Mundial da Saúde, em nível mundial, e outro produzido pelo Ministério da Saúde do Brasil como parte da ação de controle do tabagismo por meio das carteiras de cigarros vendidas no território nacional.

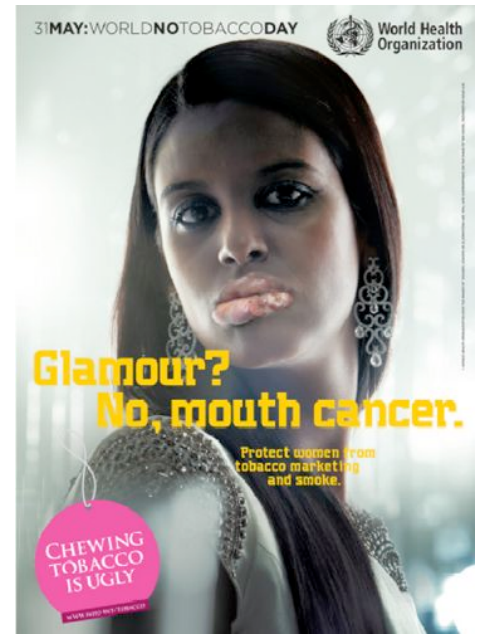

Figura 2 - Campanha antitabagismo promovida pela Organização Mundial da Saúde. Fonte: Organização Mundial da Saúde 


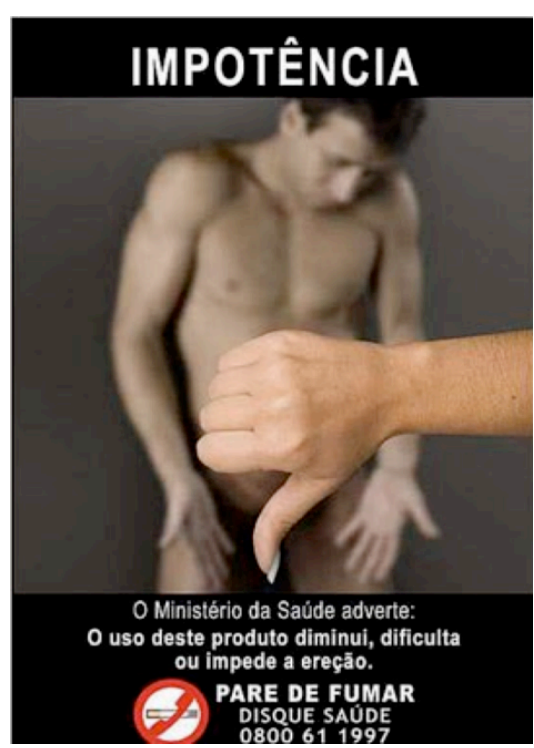

Figura 3 - Campanha antitabagismo promovida pelo Ministério da Saúde do Brasil. Fonte: Ministério da Saúde do Brasil

No primeiro caso, a imagem faz parte de uma série composta por produções que apresentam mulheres em poses e enquadramentos típicos de campanhas de moda. Elas são representadas como modelos que, devido ao hábito de fumar, desenvolveram problemas de saúde que prejudicaram suas aparências. Acompanhada da frase "mastigar ${ }^{4}$ tabaco é feio", a imagem deste cartaz sugere que ao fumar, o aumento da possibilidade de se desenvolver câncer de boca aumenta e, consequentemente, a beleza diminui. No segundo exemplo, o uso do cigarro é apontado como algo que diminui, dificulta ou impede a ereção, algo que também podemos entender como uma experiência que, de certo modo, 'arruína' ou 'devasta' a masculinidade de um homem.

Tais situações nos provocam a pensar que os discursos da saúde predominantes colocam a responsabilidade pelos cuidados com a saúde exclusivamente nas mãos dos indivíduos, produzindo, deste modo, sujeitos balizados pelos imperativos do controle de riscos. Assim, passamos a ser responsáveis pelas nossas condições físicas, entre elas a beleza e a potência corporal, por meio de uma lógica que produz verdades que reduzem estruturas disciplinares complexas a mensagens simples de causa e efeito (STREET, 2004).

Neste sentido, apesar de termos trazido, neste texto, apenas três exemplos destas campanhas, destacamos que elas representam outros materiais que se encontram em circulação por meio das paisagens urbanas, em diferentes escalas e formatos. Portanto, consideramos a

\footnotetext{
${ }^{4} \mathrm{O}$ verbo mastigar, na língua inglesa, é utilizado como uma gíria que significa fumar.
} 
ideia de 'paisagem biopolítica', ou seja, uma paisagem que se inscreve como uma forma de investimento na vida das populações, a partir da perspectiva de que, no espaço urbano, ela serve como uma pedagogia cultural, pois é nela que são apresentados para a população os enunciados e as imagens que materializam os discursos biopolíticos contemporâneos, os quais estão intimamente relacionados com o culto ao corpo.

Nas paisagens biopolíticas são postas em circulação representações de como devemos ser e nos comportar para continuarmos (ou, na maioria das vezes, nos tornarmos) sujeitos saudáveis, apresentando atributos corporais associados à beleza e à força física. Não pretendemos dizer com isso que este é o único meio de informação/educação, e sim que pode ser configurado como uma estratégia poderosa levando-se em conta que os sujeitos se encontram rodeados cotidianamente por elas. Nessa perspectiva, não precisamos apenas “estar” saudáveis e sim aparentar, fisicamente, que estamos saudáveis, isto é, mostrando-nos como agentes sociais competentes, capazes de controle do corpo. Em uma perspectiva mais ampla, a ideia de paisagem biopolítica poderia ser pensada, até mesmo, como o próprio corpo enquanto paisagem. Assim, poderíamos imaginar que a dimensão estética de nossos corpos se articula a outros níveis da paisagem e, por tanto, também representa um dado imperativo da saúde que passa a reforçar as orientações frequentemente divulgadas.

Particularmente, no que diz respeito às campanhas de prevenção ao fumo, somos provocados a pensar que quem fuma não é saudável e tal associação se configura de modos diferenciados para os corpos masculinos e femininos. Para as mulheres, as consequências mais associadas ao ato de fumar, de acordo com o material observado, são aparência envelhecida ou efeitos estéticos associados a doenças. Em relação aos homens, entre as imagens que mais circulam estão aquelas associadas à falta de força e fôlego bem como à impotência sexual e/ou a falta de virilidade.

A mensagem geral destas campanhas, ao que nos parece, relaciona-se à associação entre o ato de fumar e a imediata perda de saúde, ou seja, entre outras coisas, perda da beleza e da potência física. Além disso, percebemos demarcações de gênero operando entre aquilo que se pretende ensinar. Em outras palavras, há objetivos diferenciados para os sujeitos femininos e masculinos nos materiais educativos informativos que produzem as paisagens biopolíticas.

Provocados por uma campanha de prevenção ao fumo posta em circulação em 2005, na qual se afirmava: "Fumar você aprende. Parar de fumar a gente ensina", Meyer e 
colaboradores/as (2006) refletiram sobre as aprendizagens/desaprendizagens presentes em mensagens como estas, na potência que tais mensagens podem ter na vida cotidiana das pessoas que as leem e no que campanhas como essas têm a contribuir para os campos da educação e da saúde.

Assim como a campanha analisada por Meyer e colaboradores/as (idem), observamos que as paisagens biopolíticas parecem nos dizer e nos ensinar que, em primeiro lugar, a preocupação com a saúde, ou com a falta dela, quando associada à beleza, se configura um assunto feminino e quando associada à sexualidade (heterossexual), se manifesta como um assunto masculino. Nesta direção, ao discutir as campanhas de combate ao fumo, Darsie (2006) apresenta imagens que relacionam o envelhecimento da pele, o amarelamento e queda dos dentes, o realce de olheiras, entre outras questões estéticas, comumente voltadas às mulheres, enquanto que problemas relacionados à perda do fôlego e da potência sexual são endereçados aos homens. Além disso, dentre os ensinamentos promovidos por esses artefatos culturais, muitas vezes, o fracasso relacionado aos relacionamentos é mencionado como consequência do corpo que é prejudicado, física e esteticamente, pelo cigarro.

As paisagens biopolíticas, diferentemente dos artefatos culturais destinados a atender alguma população específica, tais como as revistas ou programas televisivos, voltam-se à “população em geral”, visto que ficam expostas nas ruas, em ambientes coletivos de saúde ou outros lugares públicos e são destinadas a todos e a qualquer um que circule por aqueles ambientes. Tais estratégias propõem um deslocamento dos discursos de um lugar que atinge determinados públicos, para outro que atua sobre o conjunto da população: mesmo que sejam estrategicamente distribuídos/posicionados para atender certa demanda, atingem (ou, potencialmente, podem atingir) a população como um todo. Nesta direção, as paisagens biopolíticas funcionam como pedagogias culturais, que operam por meio da própria cidade, assim como ressaltou Sarlo (1999).

Com a análise que aqui ensaiamos, indicamos para a potência de tais pedagogias culturais que colocam em circulação e movimentam determinadas noções de saúde e efeitos que tais noções produzem (ou podem produzir) na população, com vistas a governá-la. 


\section{Considerações Finais}

Ao discutirmos as campanhas de Promoção da Saúde relacionadas ao combate ao tabagismo, por meio da perspectiva teórica do Estudos Culturais, articulados à Educação, às tomamos como pedagogias culturais. Tendo em vista o caráter educativo em que se sustentam nos dias de hoje e o conjunto de artefatos utilizados para a circulação de suas mensagens, as campanhas discutidas acionam uma rede que se distribui pelo espaço geográfico compondo aquilo que denominamos como paisagens biopolíticas.

As paisagens biopolíticas, caracterizadas por seu caráter urbano, portanto, auxiliam naquilo que pode ser entendido como governamento da população que visa a produzir sujeitos cada vez mais preocupados e engajados com suas condições de saúde. Para além disto, nestes casos - paisagens biopolíticas relacionadas ao tabagismo - podemos pensar que tais sujeitos se tornam, também, engajados em um ideal de beleza e potência física que, de algum modo, passa a compor a paisagem - por meio do próprio corpo - e a aumentar a circulação da ideia de saúde relacionada à beleza e à força.

Diante do que apresentamos, pensamos ser importante finalizar este texto chamando a atenção para o fato de que esta é uma forma de problematizar tais questões e, sendo assim, não se fecha em si mesma. Nesta direção, é possível pensar que novas e interessantes discussões podem emergir a partir deste tipo de análise.

\section{Referências}

ANDRADE, Paula Deporte de; COSTA, Marisa Vorraber. Nos rastros do conceito de pedagogias culturais: invenção, disseminação e usos. Educ. rev., Belo Horizonte, v. 33, p. 01-23, 2017.

. Usos e possibilidades do conceito de pedagogias culturais nas pesquisas em estudos culturais em Educação. Textura, Canoas, v. 17 n. 34, p.48-63, mai./ago. 2015.

CARLOS, Ana Fani A. A (re)produção do espaço urbano. São Paulo: Edusp, 1994.

CASTIEL, Luis David. A medida do possível... saúde, risco e tecnobiociências. Rio de Janeiro: Contra Capa Livraria/Editora Fiocruz, 1999.

CASTILHO, Ricardo; FREDERICO, Samuel. Espaço geográfico, produção e movimento: uma reflexão sobre o conceito de circuito espacial produtivo. Sociedade e Natureza, Uberlândia, v. 22, n. 3, p. 461-474, dez. 2010. 
COSTA, Luís Artur. Estado dispersivo e biopolítica contemporânea: alguns percursos genealógicos da emergência do presente. In: MARASCHIN, Cleci; TIRADO, Francisco Javier. (org.). Biossegurança e biopolítica no século XXI. Abrapso, Porto Alegre, p. 201-224, 2017.

COSTA, Marisa Vorraber. ANDRADRE, Paula Deporte. Na produtiva confluência entre educação e comunicação, as pedagogias culturais contemporâneas. Perspectiva, Florianópolis, v. 33, n. 2, p. 843-862, maio/ago. 2015.

DARSIE, Camilo. Territórios de exclusão: Educação em saúde e representações de fumantes no espaço público. 2006. Dissertação (Mestrado em Educação). Universidade Luterana do Brasil - ULBRA, Canoas, 2006.

. SANTOS, Luis Henrique Sacchi. Espaço, paisagem e biotecnologia: promessas e realidades apresentadas no filme 'A ilha'. Caminhos de Geografia, Uberlândia, v. 13, n. 44, p. 249-255, Dez. 2012.

FIGUEIREDO, Débora de Carvalho; NASCIMENTO, Fábio Santiago; RODRIGUES, Maria Eduarda. Discurso, culto ao corpo e identidade: representações do corpo feminino em revistas brasileiras. Ling. (dis)curso, Tubarão, v. 17, n. 1, p. 67-88, abr. 2017.

FOUCAULT, Michel. Em defesa da sociedade: curso no Collége de France (1975-1976). Tradução Maria Ermantina Galvão. São Paulo: Martins Fontes, 1999.

HALL, Stuart. A centralidade da cultura: notas sobre as revoluções de nosso tempo. In: Educação e Realidade. v.22, n.2. Porto Alegre: Universidade Federal do Rio Grande do Sul, Faculdade de Educação, jul./dez. 1997.

HILLESHEIM, Betina. Políticas públicas e educação: desdobramentos para a pesquisa. Revistas Ibero-Americana de Estudos em Educação, Araraquara, v.10, n.3, p. 788-796, 2015.

MEYER, Dagmar; MELLO, Débora Falleiros; VALADÂO, Marina Marcos; AYRES, José Ricardo de Carvalho Mesquita. "Você aprende. A gente ensina?". Interrogando relações entre educação e saúde desde a perspectiva da vulnerabilidade. Cad. de Saúde Pública, Rio de Janeiro, v. 22, n. 6, p. 1335-1342, jun. 2006.

NETTLETON, Sarah. Governing the risk self; how to become healthy, wealthy and wise. In: PETERSEN, Alan \& BUNTON, Robin (Orgs.). Foucault, health and medicine. Routledge, London/New York, 1997.

NOGUERA-RAMIREZ, Carlos E. O governamento pedagógico: da sociedade de ensino para a sociedade de aprendizagem. 2009. 266f. Tese (Doutorado em Educação). Faculdade de Educação, Universidade Federal do Rio Grande do Sul, Porto Alegre, 2009. 
SALGUEIRO, Teresa Barata. Cidade Pós-Moderna: espaço fragmentado. In: Revista Território, Rio de Janeiro, v. 3, n. 4, jan-jul. 1997.

SANTOS, Luís H. Sacchi dos. Para onde foi a Aids? A (in)visibilidade da epidemia. In: ZAGO, Luiz F. (org.). Cadernos Obscenos - a erotização do cuidado. Volume III. Somos Comunicação, Saúde e Sexualidade, Porto Alegre, 2011.

- Dos corpos desterrados aos corpos cheios de força: representações de corpo e de saúde em anúncios de anti-retrovirais. In: SOMMER, Luís Henrique; BUJES, Maria Isabel Edelweiss. Educação e cultura contemporânea: articulações, provocações e transgressões em novas paisagens. Canoas: Ed. ULBRA, 2006.

SANTOS, Milton. A Natureza do Espaço. Técnica e Tempo. Razão e Emoção. São Paulo: Hucitec, 1997.

SARLO, Beatriz. La ciudad Vista - mercancías y cultura urbana. Buenos Aires: Siglo Veinteiuno, 2009.

SIBILIA, Paula. O homem pós-orgânico: corpo, subjetividade e tecnologias digitais. Rio de janeiro: Relume/Duramá, 2002.

SILVA, Júlio César Felix da. Categorias analíticas da Geografia: caminhos para leitura do espaço geográfico. Revista Diálogos, n. 14, ago./set. 2015.

SILVA, Tomaz Tadeu da. Documentos de identidade - uma introdução aos estudos do currículo. Belo Horizonte: Autêntica, 1999.

. O currículo como fetiche - a poética e a política do texto curricular. Belo Horizonte: Autêntica, 2000.

Autêntica, 2000.

. Teoria cultural e educação: um vocabulário crítico. Belo Horizonte:

STREET, Annette F. Ask your doctor: the construction of smoking in advertising posters produced in 1946 and 2004. In: Nursing Inquiry, v. 11, n. 4, 2004.

SUERTEGARAY, Dirce. Espaço Geográfico Uno e Multiplo. Scripta Nova, Barcelona, n. 93, 2001.

SZKLO, André Salem et al. Estratégia de recrutamento de fumantes no metrô do Rio de Janeiro, Brasil, para ampliar o acesso a linhas telefônicas de apoio à cessação: impacto da novidade. Cad. Saúde Pública, Rio de Janeiro, v. 25, n. 11, p. 2524-2528, Nov. 2009.

World Health Organization. WHO Framework Convention on Tobacco Control. Gêneva, 2003. 
WORTMANN, Maria Lúcia Castagna; COSTA, Marisa Vorraber; SILVEIRA, Rosa Maria Hessel. Sobre a emergência e a expansão dos Estudos Culturais em educação no Brasil. Rev. Educação, Porto Alegre, v. 38, n. 1, p. 32-48, jan.-abr. 2015. 